\title{
An outbreak of endophthalmitis following Intravitreal Injection of Bevacizumab in a referral center
}

\author{
Samar A Bukhatwa ${ }^{1}$, Sabah S Eldressi ${ }^{1}$, El-Said G Metmoah ${ }^{1}$, Salma A Bukhatwa ${ }^{2}$ \\ 1. Ophthalmology Department, Faculty of Medicine, University of Benghazi/ Libya \\ 2. Department of Pharmacology \& Toxicology, Faculty of Pharmacy, University of Benghazi/Libya.
}

Corresponding Author: Samar A. Bukhatwa, Address Ophthalmology department, Faculty of medicine, University of Benghazi/Libya, Phone numbers +218923005202, E-mail address samar.bukhatwa@uob.edu.ly

Received: 1-2-2021, Accepted: 24-5-2021, Published online:10-6-2021

EJO(MOC) 2021;2:85-90.

Running title: A n outbreak of endophthalmitis following Intravitreal Injection of Bevacizumab

\begin{abstract}
Purpose to- Report the largest outbreak of infectious endophthalmitis after intravitreal injection (IVI) of bevacizumab (BCZ) from a single-use vial to 14 Libyan patients.
\end{abstract}

Design- A retrospective non-comparative case series.

Methods- Medical records and microbiology results of 13 out of 14 endophthalmitis patients who were injected with BCZ on two consecutive days September 3 and September 4, 2019, were reviewed.

Results - Fourteen patients were injected by four physicians on 2 consecutive days with BCZ, prepared by a well-trained operation theatre (OT) nurse at the major operation theatre in Alkeish polyclinic under aseptic technique. All of them presented the next day with signs and symptoms of endophthalmitis, (13 out of 14 patients) were treated by intravitreal antibiotic injections as an emergency measure and they underwent PPV within 5-7 days. Microbiology results revealed that Acinetobacter baumannii was the organism responsible for the infection. After one month of the incident; One patient (7.5\%) recovered vision of $6 / 24$, four patients (31\%) had a vision of $6 / 60$, but eight patients (61.5\%) did not recover their vision and had a vision of count-fingers and less.

Conclusion- The unavailability of a single-use ampule of BCZ and its compounding from a larger volume vial is a risk that mandates following the standard guidelines for IVI for the prevention of complications.

key words- Acinetobacter baumannii, Bevacizumab, Compounding procedure, Endophthalmitis.

\section{Introduction}

Recently, intravitreal injection (IVI) became the commonest performed procedure in Ophthalmology. The usage of the intravitreal route for the administration of antivascular endothelial growth factor (VEGF) agents for the treatment of diabetic macular edema, exudative age-related macular degeneration, and retinal vaso-occlusive disease has proven to be a legitimate medical advance, and their use has evolved dramatically ${ }^{1}$.
Despite those previous studies reported acute endophthalmitis following anti-VEGF administration as a rare complication with an incidence that varies between $0.019 \%$ and $0.09^{2-3}$, endophthalmitis remains the most terrifying complication of IVI, owing to the poor prognosis of vision despite the accurate diagnosis and early management ${ }^{4}$.

IVI of bevacizumab (BCZ) has been used off-label for the treatment of exudative and neovascular ocular diseases since

Egyptian Journal of Ophthalmology, a publication of Mansoura Ophthalmic Center.

Address: Mansoura Ophthalmic Center, Mansoura University, Mansoura, Egypt.

Website: https://ejomos.journals.ekb.eg

Tel. 0020502202064. Fax. 0020502202060.

E-mail: ejo@mans.edu.eg 
May $2005^{5}$. Recent outbreaks of endophthalmitis have raised a concern about the safety of the drug-preparation process ${ }^{6-10}$.

The current study reports the largest outbreak of infectious endophthalmitis after IVI of BCZ from single-use vial to 14 Libyan patients.

\section{Materials and methods}

This study was conducted by the Martyr Soheil Al-Atrash hospital's Ophthalmologists in Alkeish polyclinic in Benghazi/ Libya in accordance with the Declaration of Helsinki recommendations.

On September 2019, a total number of 14 patients who received IVI of BCZ (Avastin ${ }^{\circledR}$; Genentech Inc., South San Francisco, CA, USA) for diabetic macular edema, developed endophthalmitis.

Reviewing the medical records of 13 patients (one patient excluded because on the first day of diagnosing her as endophthalmitis she traveled abroad immediately and was not followed up), the demographic details, best-corrected visual acuity (BCVA) before the injection, one day and one month after the injection, clinical features, microbiological findings and management were retrospectively recorded.

Statistical analyses were performed using Statistical Package for the Social Sciences (SPSS version 23.0; IBM Corporation, Armonk, N.Y., USA). Continuous data were presented as mean \pm standard deviation (SD). Categorical data expressed as numbers and percentages.

In this outbreak, the affected patients were injected with BCZ by four physicians on 2 consecutive days (6 patients received the drug on September $3^{\text {rd }}, 2019$ and 8 patients received it on September $\left.4^{\text {th }}, 2019\right)$.

IVI of BCZ was performed as an outpatient procedure at the major operation theatre in Alkeish polyclinic under strict aseptic technique.

All patients received $\mathrm{BCZ}$ that was prepared by a trained operation theatre (OT) nurse, the BCZ vial (previously stored in the refrigerator) was punctured in the early morning (one hour before the time of injection of $1^{\text {st }}$ patient on the first day of injections under the normal OT environment (due to the unavailability of the International Organization for Standardization Class 5 air quality environment ), and contents were drawn in a $2 \mathrm{ml}$ syringe that was used to fill in the other sterile insulin syringes intended to be used for IVI of $\mathrm{BCZ}$ for the patients on that day, then the $\mathrm{BCZ}$ vial was put in the refrigerator, and the following day the same procedure was repeated by re-puncturing the same vial stopper again and preparing the injections for patients scheduled for intravitreal BCZ. Sterility testing to the prepared syringes was not done before the injections on both days.

Fourteen patients who received intravitreal $\mathrm{BCZ}$ on two consecutive days; the $3^{\text {rd }}$ and $4^{\text {th }}$ of September 2019 reported to the OPD the next day complaining of severe pain associated with a decreased vision for the last few hours. A quick detailed clinical examination, along with an ocular ultrasound B-scan, was done and the diagnosis of endophthalmitis was confirmed.

\section{Emergency measures}

Immediately, the operation theatre team was informed and emergency first aid in form of intravitreal antibiotics was conducted for all the patients except one patient who refused any intervention, all the thirteen patients received intravitreal vancomycin $(1.0 \mathrm{mg} / 0.1 \mathrm{~mL})$ twice; on the day of presentation and the following day.

Samples from the vitreous tap and the BCZ vial were handed over for microbiological tests.

Pars plana vitrectomy (PPV) could not be done inside the country due to decreased technical facilities, all the thirteen patients were dispatched abroad and underwent PPV within 5-7 days post endophthalmitis.

\section{Results}

Clinical and demographic features of the thirteen (out of 14) patients who developed endophthalmitis post intravitreal injection of $\mathrm{BCZ}$ are presented in Table 1. 
Table 1: Clinical and demographic features of patients who developed endophthalmitis following intravitreal injection of bevacizumab

\begin{tabular}{ll}
\hline Features & Value $\quad$ n (\%) \\
\hline Number of patients & 13 \\
Male & $7(54 \%)$ \\
Female & $6(46 \%)$ \\
Age/years (mean $\pm \mathrm{SD})$ & $53.62 \pm 11.10$ \\
Range & $35-71$ \\
Number of patients with cataract & $5(38.5 \%)$ \\
(pre-injection) & \\
\hline
\end{tabular}

Pre-injection best corrected visual acuities (BCVA) were 6/18 (one patient, $7.5 \%$ ), 6/24 (one patient, $7.5 \%$ ), 6/36 (five patients, 38.5\%), 6/60 (six patients, 46\%) (Table 2). The changes in BCVA at the time of presentation and one month after the presentation (after receiving treatment) are shown in Table 2.

Table 2: Visual acuity prior to endophthalmitis, at presentation, and at one-month follow-up after receiving treatments $(\mathrm{n}=13)$.

\begin{tabular}{|c|c|c|c|}
\hline $\begin{array}{l}\text { Best } \\
\text { Corrected } \\
\text { Visual } \\
\text { Acuities } \\
\text { (BCVA) }\end{array}$ & $\begin{array}{l}\text { Prior to } \\
\text { endophthalmitis } \\
\text { n (\%) }\end{array}$ & $\begin{array}{l}\text { At } \\
\text { presentation } \\
\text { n (\%) }\end{array}$ & $\begin{array}{l}\text { One month } \\
\text { after } \\
\text { receiving } \\
\text { treatment } \\
\text { n (\%) }\end{array}$ \\
\hline $6 / 18$ & $1(7.5 \%)$ & - & - \\
\hline $6 / 24$ & $1(7.5 \%)$ & - & $1(7.5 \%)$ \\
\hline $6 / 36$ & $5(38.5 \%)$ & - & - \\
\hline $6 / 60$ & $6(46 \%)$ & - & $4(31 \%)$ \\
\hline $\mathrm{CF}$ & - & - & $2(15.5 \%)$ \\
\hline HM & - & $1(7.5 \%)$ & $6(46 \%)$ \\
\hline LP & - & $12(92.5 \%)$ & - \\
\hline
\end{tabular}

CF; Count-figures, HM; Hand motion, LP; Light perception

Five patients were having cataract prior to endophthalmitis; three of them had lens removal with intra ocular lens implant during vitrectomy; one of them had a BCVA of 6/36 after surgery, and the other two had BCVA of counting-fingers.

After one month of the incident; eight patients (61.5\%) did not recover their vision and had a vision of count-fingers and less (Table 2).

\section{Microbiological results}

The organism responsible for the endophthalmitis was confirmed to be Acinetobacter baumannii.

\section{Discussion}

Endophthalmitis following intravitreal injection is uncommon ${ }^{2-3,11-12}$. In the current study, fourteen patients developed endophthalmitis after receiving IVI of BCZ; and although it was discovered very early from the $1^{\text {st }}$ follow-up day, the infection was by a very virulent organism and all patients did need vitrectomy after which some of them recovered a little of their vision.

There are multiple reports on endophthalmitis outbreaks following the intravitreal use of $\mathrm{BCZ}^{13-16}$. In the present study, the organism was Acinetobacter baumannii, which is a gram-negative bacterium that is considered to be an important nosocomial pathogen in the last decade. It affects multiple systems throughout the body with inherent resistance to numerous antibiotics due to extended-spectrum betalactamase production and alterations in its outer membrane ${ }^{3,17}$.

There is not much information about endophthalmitis caused by Acinetobacter baumannii in the literature. Çankaya $\mathrm{C}$ et al. reported acute Acinetobacter baumannii endophthalmitis following intravitreal Ranibizumab injection in a patient having age-related macular degeneration; in which despite the prompt use of intravitreal antibiotics, ended by the patient losing his vision ${ }^{17}$. The same results were reported by Chen and his colleagues who isolated the same pathogen in two cases, one was a case of endogenous endophthalmitis and the other was post-keratoplasty endophthalmitis with no improvement after treatment ${ }^{18}$.

In contrast, Bitirgen et al reported a complete recovery of vision to $20 / 20$ in a case of post phacoemulsification endophthalmitis and they owed this to proper evaluation and, well-timed vitrectomy, and appropriate medication ${ }^{19}$.

In the present study, one patient $(7.5 \%)$ recovered vision of $6 / 24$, four patients $(31 \%)$ had a vision of $6 / 60$, but eight patients $(61.5 \%)$ did not recover their vision and had a vision of count-fingers and less. These poor visual outcomes are 
most probably due to delayed vitrectomy (5-7 days) post endophthalmitis.

Most of the literature on endophthalmitis post intravitreal injection describe the precautions during the injection to prevent the infections without giving attention to the drug preparation $^{6}$. The unavailability of a single-use ampule of $\mathrm{BCZ}$ and its compounding from a larger volume vial is considered a challenge toward sterility ${ }^{20-21}$. BCZ is used 'offlabel' and it is prepared, at all events, by the compounding pharmacies or skilled OT nurses; which add a step between the manufacturer and physician that may cause its contamination $^{22}$.

According to the United States Pharmacopeia (USP) chapter 797 standards, any single-dose vial when punctured or opened under the International Organization for Standardization Class 5 air quality environment must be used completely within 6 hours $^{23}$.

If the conditions were worse than the International Organization for Standardization Class 5 air quality environment when the vial is punctured, it should not be used after one hour and not be stored, otherwise, the risk of infection would be high ${ }^{24}$.

$\mathrm{BCZ}$ vials are single-use, preservative-free that have an increased risk to be contaminated when their rubber stopper is penetrated more than once; a condition that entails the Mini-Spike Dispensing device usage that permits single penetration to the vial and then dispensing the solution into multiple insulin syringes with detachable needles ${ }^{25}$. The use of an Insulin syringe with nondetachable needles increases the risk of contamination, dulls the needle making it painful to the patient during injection, and lastly, the droplets of the $\mathrm{BCZ}$ that remain in the needles' lumen may precipitate over time causing particulate contamination ${ }^{25}$. After preparing the syringes, sterility testing should be randomly performed on $10 \%$ of the prepared syringes and the syringes should be stored at the proper temperature and discarded after 2 weeks ${ }^{25-}$ 26 .

So, drug compounding from a larger volume vial adds risk for the procedure and may end by the occurrence of endophthalmitis.
Overall, in case of shortage of facilities, then the surgeon should gather the patients on the injection day, prepare the aliquots by a single puncture to the vial, one syringe for each patient, using detachable syringes under complete aseptic technique, then the vial should be discarded and not be reused again $^{25,27}$.

According to Gonzalez et al., the drug is innocent, it is all about human error and the compounding procedure ${ }^{25}$.

\section{In conclusion}

Endophthalmitis is a preventable complication that can be minimized or even avoided if the standard guidelines for IVI are followed during the compounding procedures while preparing IVI of BCZ.

\section{Corresponding author}

Correspondence to Samar A. Bukhatwa

Email: samar.bukhatwa@uob.edu.ly

\section{Ethics declarations}

\section{Conflict of interest}

Samar A Bukhatwa, Sabah S Eldressi, El-Said G Metmoah, Salma A Bukhatwa, all authors have no conflicts of interest that are directly relevant to the content of this review.

Funding: No sources of funding were used to conduct this review.

Reviewer disclosures: No relevant financial or other relationships to disclose.

Declaration of interest: No financial affiliations or financial involvement with any organization or entity with a financial competing with the subject matter or materials discussed in the review.

\section{References}

1. Lanzetta P, Mitchell P, Wolf S, Veritti D. Different antivascular endothelial growth factor treatments and regimens and their outcomes in neovascular age-related macular degeneration: a literature review. $\mathrm{Br} \quad J$ Ophthalmol. 2013 Dec;97(12):1497-507.

2. Mason JO, White MF, Feist RM, Thomley ML, Albert MA, Persaud TO, et al. Incidence of acute onset endophthalmitis following intravitreal bevacizumab (Avastin) injection. Retina. 2008 Apr;28(4):564-7. 
3. Bhavsar AR, Googe JM, Stockdale CR, Bressler NM, Brucker AJ, Elman MJ, et al. Risk of endophthalmitis after intravitreal drug injection when topical antibiotics are not required: the diabetic retinopathy clinical research network laser-ranibizumab-triamcinolone clinical trials. Arch Ophthalmol. 2009 Dec;127(12):1581-3.

4. Sachdeva MM, Moshiri A, Leder HA, Scott AW. Endophthalmitis following intravitreal injection of antiVEGF agents: long-term outcomes and the identification of unusual micro-organisms. J Ophthalmic Inflamm Infect. 2016 Dec;6(1):2.

5. Rosenfeld PJ, Fung AE, Puliafito CA. Optical coherence tomography findings after an intravitreal injection of bevacizumab (avastin) for macular edema from central retinal vein occlusion. Ophthalmic Surg Lasers Imaging. 2005 Aug;36(4):336-9.

6. Goldberg RA, Flynn HW, Isom RF, Miller D, Gonzalez S. An outbreak of streptococcus endophthalmitis after intravitreal injection of bevacizumab. Am J Ophthalmol. 2012 Feb;153(2):204-208.e1.

7. Sato T, Emi K, Ikeda T, Bando H, Sato S, Morita S, et al. Severe intraocular inflammation after intravitreal injection of bevacizumab. Ophthalmology. 2010 Mar;117(3):512-6, 516.e1-2.

8. Lee SH, Woo SJ, Park KH, Kim JH, Song JH, Park KU, et al. Serratia marcescens endophthalmitis associated with intravitreal injections of bevacizumab. Eye Lond Engl. $2010 \mathrm{Feb} ; 24(2): 226-32$.

9. More Reports of Avastin Injections Causing Blindness The New York Times. [accessed 2019 Nov 10]. Available from:https:/www.nytimes.com/2011/09/02/business/mor e-reports-of-avastin-causing-blindness.html

10. Centers for Disease Control and Prevention (CDC). Notes from the field: Multistate outbreak of postprocedural fungal endophthalmitis associated with a single compounding pharmacy - United States, MarchApril 2012. MMWR Morb Mortal Wkly Rep. 2012 May 4;61(17):310-1.

11. McCannel CA. Meta-analysis of endophthalmitis after intravitreal injection of anti-vascular endothelial growth factor agents: causative organisms and possible prevention strategies. Retina. 2011 Apr;31(4):654-61.

12. Moshfeghi AA, Rosenfeld PJ, Flynn HW, Schwartz SG, Davis JL, Murray TG, et al. Endophthalmitis after intravitreal vascular [corrected] endothelial growth factor antagonists: a six-year experience at a university referral center. Retina. 2011 Apr;31(4):662-8.

13. Wang F, Yu S, Liu K, Chen F-E, Song Z, Zhang X, et al. Acute intraocular inflammation caused by endotoxin after intravitreal injection of counterfeit bevacizumab in Shanghai, China. Ophthalmology. 2013 Feb;120(2):35561.

14. Whalen CW and J. How Fake Cancer Drugs Entered U.S. Wall Street Journal. 2012 Jul 20 [accessed 2020 Mar 5]; Available from: https://www.wsj.com/articles/SB1000142405270230387 9604577410430607090226

15. Garcia-Aguirre G, Vanzinni-Zago V, Quiroz-Mercado H. Growth of Scytalidium sp. in a counterfeit bevacizumab bottle. Indian J Ophthalmol. 2013 Sep $1 ; 61(9): 523$.

16. Agarwal AK, Aggarwal K, Samanta R, Angrup A, Biswal M, Ray P, et al. Cluster endophthalmitis due to Stenotrophomonas maltophilia following intravitreal bevacizumab: outcomes of patients from North India. $\mathrm{Br}$ J Ophthalmol. 2019 Sep 1;103(9):1278-83.

17. Çankaya C, Cumurcu T, Doğanay S. Acinetobacter Baumannii Endophthalmitis Following Intravitreal Ranibizumab Injection. Ret-Vit. 2013;21:59-62.

18. Chen K-J, Hou C-H, Sun M-H, Lai C-C, Sun C-C, Hsiao C-H. Endophthalmitis Caused by Acinetobacter baumannii: Report of Two Cases. J Clin Microbiol. 2008 Mar 1;46(3):1148-50.

19. Bitirgen G, Ozkagnici A, Kerimoglu H, Kamis U. Acute postoperative endophthalmitis with an unusual infective agent:Acinetobacter baumannii. J Cataract Refract Surg. 2013 Jan;39(1):143-144.

20. Khan P, Khan L, Mondal P. Cluster endophthalmitis following multiple intravitreal bevacizumab injections 
from a single use vial. Indian J Ophthalmol. 2016 Sep;64(9):694-6.

21. Frenkel RE, Haji SA, La M, Frenkel MP, Reyes A. A protocol for the retina surgeon's safe initial intravitreal injections. Clin Ophthalmol. 2010;4:1279-85.

22. Schwartz SG, Flynn HW. Endophthalmitis Associated with Intravitreal Anti-Vascular Endothelial Growth Factor Injections. Curr Ophthalmol Rep. 2014 Mar 1;2(1):1-5.

23. Compounding Pharmacies. [accessed 2020 Mar 5]. Available from: https://www.texwipe.com/compoundingpharmacies?gclid=EAIaIQobChMIwemTmqOD6AIVyb HtCh1RbghcEAAYASAAEgKMZPD_BwE

24. Liu L, Ammar DA, Ross LA, Mandava N, Kahook MY, Carpenter JF. Silicone Oil Microdroplets and Protein
Aggregates in Repackaged Bevacizumab and Ranibizumab: Effects of Long-term Storage and Product Mishandling. Invest Ophthalmol Vis Sci 2011;52(2):1023-1034.

25. Gonzalez S, Rosenfeld PJ, Stewart MW, Brown J, Murphy SP. Avastin Doesn't Blind People, People Blind People. Am J Ophthalmol. 2012 Feb 1;153(2):196-203.e1. 26. usp31nf26s1_c71, General Chapters: $<71>$ STERILITY TESTS. [accessed 2020 Mar 7]. Available from: http://www.uspbpep.com/usp31/v31261/usp31nf26s1_c7 1.asp

27. Kumar A, Ravani R. Using intravitreal bevacizumab (Avastin $\left.{ }^{\circledR}\right)$ - Indian Scenario. Indian J Ophthalmol. 2017 Jul 1;65(7):545. 